\title{
Features of environmental factors to ensure the environmental safety of urban planning complexes
}

\author{
Vadim Bespalov ${ }^{1}$, and Ekaterina Kotlyarova ${ }^{1, *}$ \\ ${ }^{1}$ Department of Environmental Engineering, Don State Technical University, 344006 Rostov-on-Don, \\ Russian Federation
}

\begin{abstract}
The problem of integrated accounting of environmental factors to ensure the environmental safety of urban complexes is currently not fully resolved. To solve it, we propose to consider the factors of the urban environment at three main territorial levels: macro level, meso level and micro level. At the same time, those that are most important for the integrated consideration of environmental factors to ensure environmental safety at a specific level should be separately identified. In our opinion, further research in this direction should be based on the correct identification and detailed consideration of factors affecting the urban environment, followed by an assessment of impact levels. According to the results of the research stage, it can be concluded that the achievement of the environmental safety of the urban-planning territorial complexes is possible only with the improvement of the existing scientific and methodological base in the field of preliminary assessment of the level of environmental impacts and the selection of appropriate measures. Undoubtedly, such an approach can bring closer the achievement of the global goal in the field of sustainable urban development, making a comprehensive assessment of the environmental impact of influencing factors more informative and accurate.
\end{abstract}

\section{Introduction}

Historically it was formed that urbanized areas are centers of socio-economic, scientific, industrial and commercial development in most countries of the world [1]. According to forecasts [2] by 2030 the number of urban residents will be more than 5 billion people, which makes it necessary to have effective urban planning and management methods to solve various problems associated with urbanization, including in terms of control, stabilization and subsequent reduction of the continuous impact of this process to the environment.

The problem of the functioning of the city as a dependent ecosystem became the essence of one of the seventeen Sustainable Development Goals which entered into force on January 1, 2016. Taken together, the objectives are designed to balance the three

* Corresponding author: ekkot.arch@gmail.com 
interdependent aspects of the sustainable development of urbanized areas - ecological, economic and social.

In addition, the increase in anthropogenic pressures on the environment, to the extent threatening the reproduction of natural resources, including those from urban-planning territorial complexes, is one of the most significant points of the Strategy for the Scientific and Technological Development of the Russian Federation, adopted at the end of 2016 emphasizes the relevance of the researches in this area.

A sufficiently large amount of research is devoted to the problem of ensuring the environmental safety of urbanized territories, including urban planning complexes, at present it can only be said about the formation of this research area and the beginning of the formation of the corresponding methodological support for it. This issue is particularly relevant in the light of the gradual restructuring of current urban planning processes in accordance with the postulates of the concept of sustainable development of urban areas.

\section{Materials and Methods}

Currently, various types of assessments of the state of the environment in urbanized areas, including the town-planning territorial complexes, have been developed in sufficient detail, for calculation of which data on functional zoning, area and nature of development, population density, degree of landscaping, level of amenities, security of communal and social infrastructure, the nature and level of pollution of individual components of the environment (air basin, soil and vegetation ditches, water bodies), including the degree of impact of various physical fields (noise, vibration, radiation, electromagnetic radiation, thermal field) [3,4]. The implementation of such assessments involves a comprehensive solution of environmental, economic, social, sanitary and hygienic, technical, organizational and other multifactorial tasks.

Our analysis of scientific and methodological approaches to the determination of the state of the environment in the territory of town-planning territorial complexes allowed us to identify three methodological directions for assessing the state of the environment [4]:

- determination of environmental indicators characterizing the amount of environmental pollution of urban-planning territorial entities;

- determination of economic indicators, which are based on the cost characteristics of the impact of various types of pollution on the environment of urban areas;

- the definition of social indicators, which are based on socio-demographic and health characteristics characteristic of the territory under consideration and directly related to the state of the environment.

For further improvement of the methodology for the integrated assessment of the level of environmental safety of urban areas, as well as for the subsequent selection of environmentally efficient and cost-effective organizational, technical and special engineering and environmental measures to ensure the environmental safety of urban areas, including town-planning territorial complexes, we analyzed proposed approaches with the identification of positive features that we have taken in our work as basic scientific postulates. As a scientific basis for the study, we used the main provisions, conclusions and dependencies formulated in the above theoretical approaches.

The extensive and deep interrelationships of the production and social environments determine the system of locating populated places in a certain territory as productionresidential territorial complexes. Natural and climatic factors have a significant influence on their formation. In modern scientific approaches to the study of the environmental safety of such town-planning territorial complexes, environmental factors of the urban environment are considered at three main levels: macro level, meso level and micro level $[5]$. 
At the macro level, corresponding to the regional layout design of a group of populated areas, when the decisive role in the placement and formation of urbanized areas is primarily defined by economic facilities, including production structures, the principles environmental factors:

- suitability for construction;

- medico-geographical and sanitary-hygienic conditions for the formation of populated areas;

- recreational resources of the areas of settlement;

- aesthetic characteristics of the area associated with the potential for the formation of the future landscape and space-planning decisions of the built-up area.

At the same time, a comprehensive analysis of climatic conditions at the settlement level shows that their strongest influence is manifested in determining:

- zones of reference (with the most favorable climatic conditions) and stable (with satisfactory conditions for the formation of permanent settlements) settlement, as well as mobile resettlement (with extreme climatic conditions and the limited duration of the settlements);

- types of settlements in the areas of new economic development (permanent, temporary, mobile);

- inter-recreational zones with the inclusion of all types of recreation (short and long summer and winter recreation, tourism, sports, hunting, fishing, stationary recreation, treatment).

At the meso-level corresponding to the district layout of several populated areas, the factors affecting the surrounding urban environment of individual industrial facilities and urban facilities, including life support systems, are considered in more detail. In this case, the city-planning decisions made at the macro level on the placement of industrial, residential and recreational areas are specified with the regional planning of several settlements, individual urban areas and suburban areas [6].

Significant impact on the planning organization of populated areas have the methods of engineering preparation of the territories: the preservation of the quality of water resources, air, soil and vegetation as close as possible to the natural (original).

The main method of solving problems of assessing the level of environmental safety of urbanized areas at the meso-level is the method of assessing environmental factors: noise, vibration, gas, dust, ionizing radiation, electromagnetic field, aeration mode of the territory, thermal radiation and others.

This method includes two main steps:

- factor assessment, which consists in determining the level of impact of each factor allocated for the territory under consideration. At the same time, on the basis of the obtained factor assessments, the corresponding assessment groups of the territory under consideration are formed:

- landscape assessment, determined on the basis of the characteristics of the terrain, structure and saturation of vegetation, as well as the presence, types and configuration of water bodies (water bodies and watercourses);

- climatic assessment, determined on the basis of the values of temperature and humidity of the air, wind regime, as well as the level of solar radiation (insolation) and the magnitude of the temperature inversion;

- engineering-geological assessment, determined on the basis of an analysis of the soil structure, its chemical composition, the presence and characteristics of mineral resources; - communication assessment, determined on the basis of the characteristics of all transport and communication links in the infrastructure of the urban environment under consideration; 
- medical-geographical assessment, determined on the basis of analysis of weather and climatic conditions from the standpoint of favorable influence and preservation of health of the population of the territory in question.

- a comprehensive assessment, consisting in the superposition consideration of the cumulative effects of certain factors determined at the first stage (with a factorial assessment).

At the same time, the main objective of a comprehensive assessment of the state of the environment and the level of ecological safety of the urbanized territory under consideration is to establish a specific mutual correspondence of the diverse needs and types of economic use of this territory to the requirements of ensuring environmental safety (environmental standards for all influencing factors). This allows to interpret the problem of ensuring environmental safety in a territorial aspect, i.e. to substantiate a differentiated approach to the use of newly developed and already formed, but intensively developing, territories on the basis of a comprehensive assessment of the state of the urban environment [4].

Comprehensive assessment of the state of the environment of a specific territory is based on consideration of two groups of factors characterizing sanitary and hygienic and environmental conditions, taking into account their importance for various types of national economic use of territories and the expected ways of its urban development [3, 4].

\section{Results}

Thus, the integrated assessment of the state of the environment in the city means an integral assessment of private assessments, a comparative planning assessment of individual areas of the entire urbanized territory under consideration, based on a set of natural and anthropogenic factors favoring the main types of economic activity [3, 4].

Ultimately, a comprehensive assessment is displayed on the map of the urban ecological zoning of an urbanized territory, identifying problematic environmental situations arising in one or another part of it. Moreover, by a problem ecological situation, many authors understand such a local state of the environment or its individual components with a corresponding level of environmental safety that differs from the normative values of each influencing factor for the worse [5].

Currently, in the transition from the analysis of individual factors (factor assessment) to the analysis of their total impact (integrated assessment) to ensure the possibility of comparing the disparate characteristics of environmental factors, most studies use the scoring method [3]. The points are determined by the method of expert evaluation (unfavorable factors get a mark with a minus sign, favorable ones - with a plus sign). As a result of the addition of points, a quantitative assessment of the state of the environment is obtained according to the combination of the factors considered, taking into account the clearly expressed territorial aspect of the problem of the surrounding urban environment, in its integrated assessment, the graphic-analytical method is used to sequentially superimpose the analysis of each factor. As a result, a map is obtained of a comprehensive assessment of the state of the environment of a specific territory.

Such a comprehensive assessment is carried out on the basis of the conditions for the formation of a favorable environment for the vital activity of the population. As a result of the assessment of the degree of discomfort, the conditions for vital activity in the regional borders under consideration can serve as a basis for developing requirements for improving microclimatic and sanitary conditions, as well as developing schemes for planning restrictions, a set of measures to ensure environmental safety and functional zoning of this area its development under new construction. 


\section{Discussion}

The method of integrated assessment deserves special attention as a possible basis for designing not only the basic elements of the urban environment, but also the abovementioned life support systems, making it possible to assess the level of the impact of these systems on the surrounding urban environment with the subsequent choice of their design, renovation or operation being optimal for the environmental efficiency values.

At the micro level, the relevant consideration of the territories of individual populated areas or their districts, consider in more detail the influence of the identified influencing factors on the functional zoning of the territory, the planning organization of development and the design of life support systems.

Analysis of many authors' research results [3, 6, 7, 8, 9] allows us to conclude that in this case a comprehensive assessment of the environmental impact of influencing factors is also carried out in order to clarify or confirm the results of a comprehensive assessment carried out at the meso level After such a refinement, it is also possible to select the optimal in terms of the environmental performance of the options for designing, reconstructing or operating both the basic elements of the urban environment and life support systems. In this case, as one of the main methods, the development of relatively unsuitable areas of the territory under consideration can be implemented for advance engineering engineering activities using favorable areas of this territory for organizing landscaping systems ("green frames") and recreational areas.

The main task in solving the problems of development of urbanized areas at the micro level is to preserve the landscape, as well as the state of water resources and the air basin at a level not exceeding the maximum permissible environmental loads $[6,8]$.

\section{Conclusions}

Thus, the analysis of research results in the field of ensuring environmental safety of urbanized areas, including urban facilities (life support systems) suggests that further research in this direction should be based on the correct identification and detailed consideration the factors affecting the urban environment. with subsequent assessment of exposure levels. Moreover, to ensure maximum objectivity of the results obtained, such an assessment, depending on the tasks set, should be carried out at the appropriate territorial levels: macro level, meso level and micro level.

According to the results of our research phase, we can conclude that the achievement of the environmental safety of town-planning territorial complexes is possible only with the improvement of the existing scientific and methodological base in the field of preliminary environmental impact assessment in the design, construction and operation of urban facilities, followed by the selection of appropriate measures. Undoubtedly, such an approach can bring closer the achievement of the global goal in the field of sustainable urban development, making a comprehensive assessment of the environmental impact of influencing factors more informative and accurate.

\section{References}

1. R. T. Forman, Urban Ecology: Science of Cities, Cambridge University Press, 462 p. (2014)

2. State of World Population, UNFPA, 108 p. (2007) 
3. E. V. Kotlyarova Improving the Methodology of Environmental and Economic Assessment of the Condition of the Territories of Industrial Zones and Justification of Environmental Protection Activities, Rostov State Civil Engineering University, 160 p.

4. V. I. Bespalov and E. V. Kotlyarova, Terra Economicus, 4-3 (9), pp. 121-123 (2011)

5. V. I. Bespalov, E. V. Kotlyarova and A. S. Bondarenko, Inzhenernuy vestnik Dona, 1, (2019)

6. S. G. Sheina and A. A. Khamavova, Procedia Engineering, pp. 1960-1965 (2016)

7. V. Ilyichev, S. Emelyanov, V. Kolchunov, N. Bakayeva and S. Kobeleva, Procedia Engineering, 117, pp. 126-131 (2015)

8. V. M. Jayasooriya, A. W. M. Ng, S. Muthukumaran and S. Perera, Urban Forestry \& Urban Greening, 21, pp. 34-47 (2017)

9. R. G. G. Caiado, Dias R. Freitas, L. V. Mattenvironment, O. L. G. Quelhas and W. L. Filho, Journal of Cleaner Production, 165, pp. 890-904 (2017) 